\title{
High-Frequency, Crosswell Radar Data Collected in a Laboratory Tank
}

Digital Data Series 486 



\section{High-Frequency, Crosswell Radar Data Collected in a Laboratory Tank}

By Bas Peters, Craig W. Moulton, Karl J. Ellefsen, Robert J. Horton, and Jason R. McKenna

Digital Data Series 486

U.S. Department of the Interior

U.S. Geological Survey 


\title{
U.S. Department of the Interior \\ KEN SALAZAR, Secretary \\ U.S. Geological Survey \\ Marcia K. McNutt, Director
}

\section{U.S. Geological Survey, Reston, Virginia: 2010}

\author{
For more information on the USGS — the Federal source for science about the Earth, its natural and living resources, \\ natural hazards, and the environment, visit http://www.usgs.gov or call 1-888-ASK-USGS \\ For an overview of USGS information products, including maps, imagery, and publications, \\ visit http://www.usgs.gov/pubprod \\ To order this and other USGS information products, visit http://store.usgs.gov
}

\begin{abstract}
Any use of trade, product, or firm names is for descriptive purposes only and does not imply endorsement by the U.S. Government.

Although this report is in the public domain, permission must be secured from the individual copyright owners to reproduce any copyrighted materials contained within this report.
\end{abstract}

Suggested citation:

Peters, Bas, Moulton, Craig W., Ellefsen, Karl J., Horton, Robert J., and McKenna, Jason R., 2010, High-frequency, crosswell radar data collection in a laboratory tank: U.S. Geological Survey Data Series, 486, 12 p. 


\section{Contents}

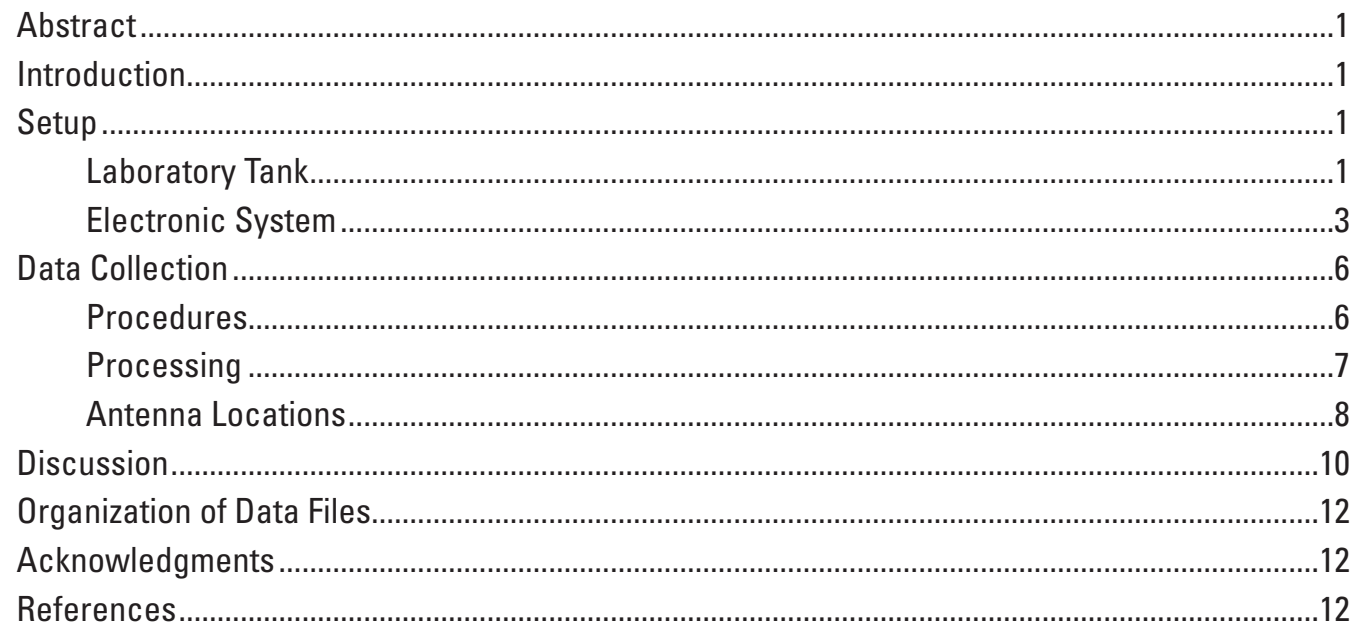

\section{Figures}

1. Photograph showing laboratory tank and scaffolding .....................................................

2. Photograph showing top of the laboratory tank, showing the three wells used to collect radar data

3-5. Schematic diagrams showing-

3. Laboratory tank; $(A)$ aerial view of top of the tank; $(B)$ cross section through the middle of the tank .............................................................................................

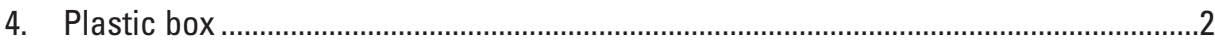

5. Well showing how various measurements of $(A)$ length and $(B)$ orientation

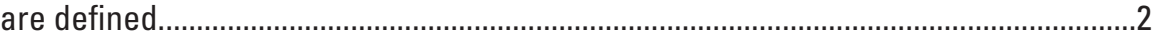

6. Graphs showing electromagnetic properties of the dry sand ........................................

7. Photograph showing transmitting antenna ....................................................................... 4

8. Schematic diagram of the electronic system.....................................................................

9. Graphs showing common-offset gathers (with zero offset) for the 6 datasets ..............10

10. Graphs showing three common-offset gathers................................................................11

\section{Tables}

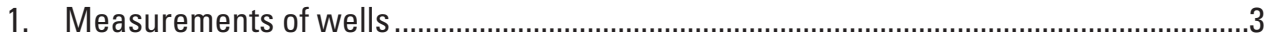

2. Data-collection parameters ...................................................................................................

3. Order in which the gathers were collected for a dataset ...................................................

4. Datasets collected between the wells....................................................................................

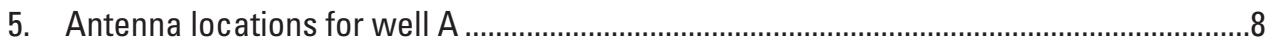

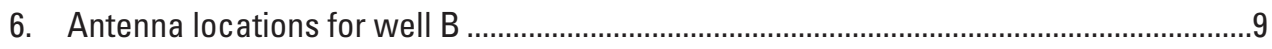

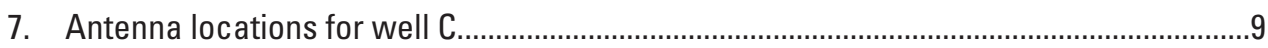




\section{Conversion Factors}

\begin{tabular}{lcl}
\hline \multicolumn{1}{c}{ Multiply } & \multicolumn{1}{c}{ By } & \multicolumn{1}{c}{ To obtain } \\
\hline centimeter $(\mathrm{cm})$ & 0.3937 & inch (in.) \\
decibel $(\mathrm{dB})$ & $10^{-1}$ & bel \\
gigahertz $(\mathrm{GHz})$ & $10^{-9}$ & hertz $(\mathrm{Hz})$ \\
kilohertz & $10^{-3}$ & hertz $(\mathrm{Hz})$ \\
meter $(\mathrm{m})$ & 3.281 & foot $(\mathrm{ft})$ \\
meter per second $(\mathrm{m} / \mathrm{s})$ & 3.281 & foot per second $(\mathrm{ft} / \mathrm{s})$ \\
microsecond & $10^{-6}$ & second $(\mathrm{s})$ \\
millimeter $(\mathrm{mm})$ & 0.03937 & inch $(\mathrm{in})$. \\
nanosecond $(\mathrm{ns})$ & $10^{-9}$ & second $(\mathrm{s})$ \\
picosecond $(\mathrm{ps})$ & $10^{-12}$ & second $(\mathrm{s})$ \\
\hline
\end{tabular}




\title{
High-Frequency, Crosswell Radar Data Collected in a Laboratory Tank
}

\author{
By Bas Peters, Craig W. Moulton, Karl J. Ellefsen, Robert J. Horton, and Jason R. McKenna
}

\begin{abstract}
Crosswell radar data were collected among three wells in a laboratory tank filled with dry sand. Embedded within the sand was a long plastic box, which was the target for the data collection. Two datasets were collected between each pair of wells, making a total of six datasets. The frequencies in the data ranged from 0.5 to 1.5 gigahertz, and the peak frequency was 0.9 gigahertz. The data are well suited for evaluating various processing algorithms, and the data linearly scale to typical field conditions.
\end{abstract}

\section{Introduction}

The crosswell radar method is used to image heterogeneity between wells in the ground (Paillet and Ellefsen, 2005). A straightforward way to assess the accuracy of an image is to compare it to the in place heterogeneity. Such a comparison is expensive in a field setting but inexpensive in a laboratory setting, so high-frequency crosswell radar data were collected in a laboratory tank filled with dry sand. Embedded within the sand was a long plastic box, which was the target for the data collection.

This report describes the configuration of the laboratory tank, the electronic system used to collect the data, the collection procedures, the processing of the data, the accuracy of the data, and the organization of the data files. Funding for this work was provided by the U.S. Army Engineer Research and Development Center.

\section{Setup}

\section{Laboratory Tank}

The laboratory tank (fig. 1) is cylindrical; its walls are high-density polyethylene and are $0.76 \pm 0.05$ centimeter $(\mathrm{cm})$ thick. Above the tank is a wooden scaffold on which personnel can stand or sit to make geophysical measurements; access to the scaffold is by stairs. The tank is filled with dry, well-sorted sand. Embedded within the sand is an air-filled box with plastic walls, which are roughly $0.6 \mathrm{~cm}$ thick.

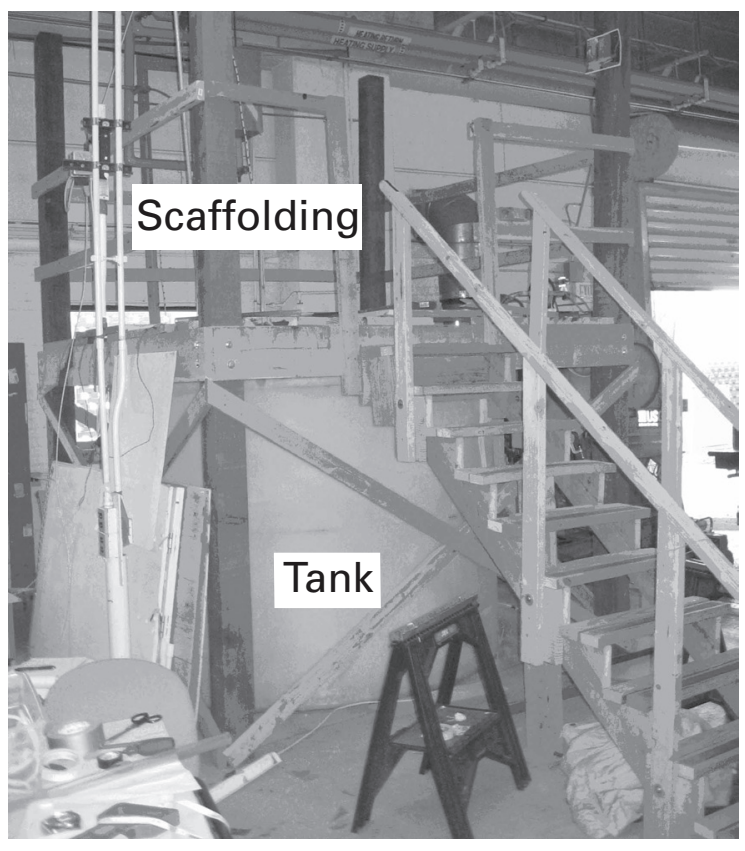

Figure 1. Laboratory tank and scaffolding.

Three vertical, air-filled wells penetrate the dry sand (fig. 2). The wells are constructed of plastic pipe with an outside diameter of $2.69 \pm 0.05 \mathrm{~cm}$, inside diameter of $2.01 \pm 0.05 \mathrm{~cm}$, and wall thickness of $0.35 \pm 0.05 \mathrm{~cm}$. The three wells are labeled A, B, and C. The top of well A is chosen as the origin of a Cartesian coordinate system that is used to assign locations within the tank. The $x$-axis points toward well $\mathrm{B}$, the $z$-axis points upward, and the $y$-axis is chosen to make the system right handed.

The configuration of the tank is shown in the schematic diagrams of figure 3 . The $x$ and $y$ coordinates of the tank center are $52.5 \pm 2.0 \mathrm{~cm}$ and $-59.7 \pm 2.0 \mathrm{~cm}$, respectively. The plastic box is located exactly halfway between wells A and B. The box also is between wells $\mathrm{B}$ and $\mathrm{C}$ but is oblique to the vertical plane passing through these two wells. The box is not between wells $\mathrm{A}$ and $\mathrm{C}$. The dimensions of the plastic box are shown in the schematic diagram of figure 4 . Several measurements of the wells are needed to accurately locate the antennas, and these measurements are defined in figure 5 and are listed in table 1. 


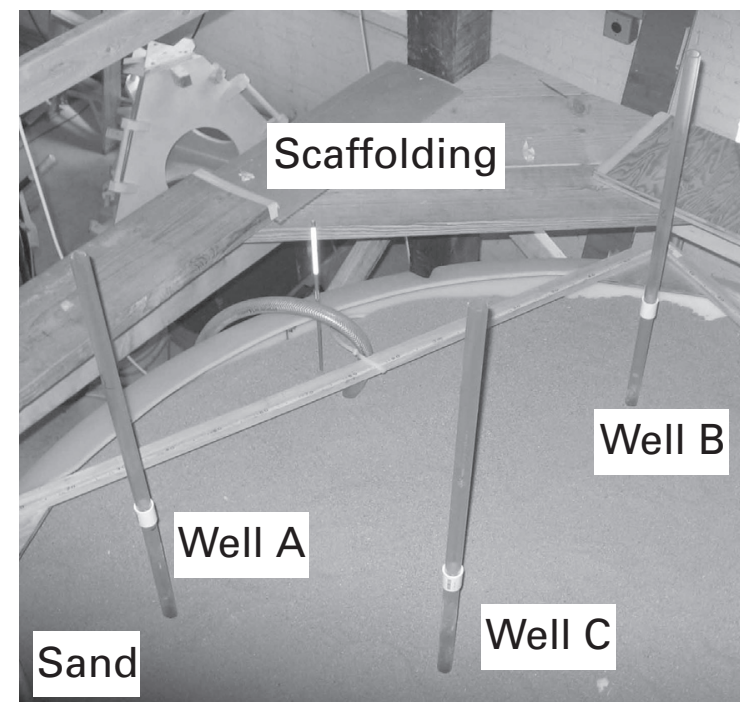

Figure 2. Top of the laboratory tank, showing the three wells used to collect radar data.
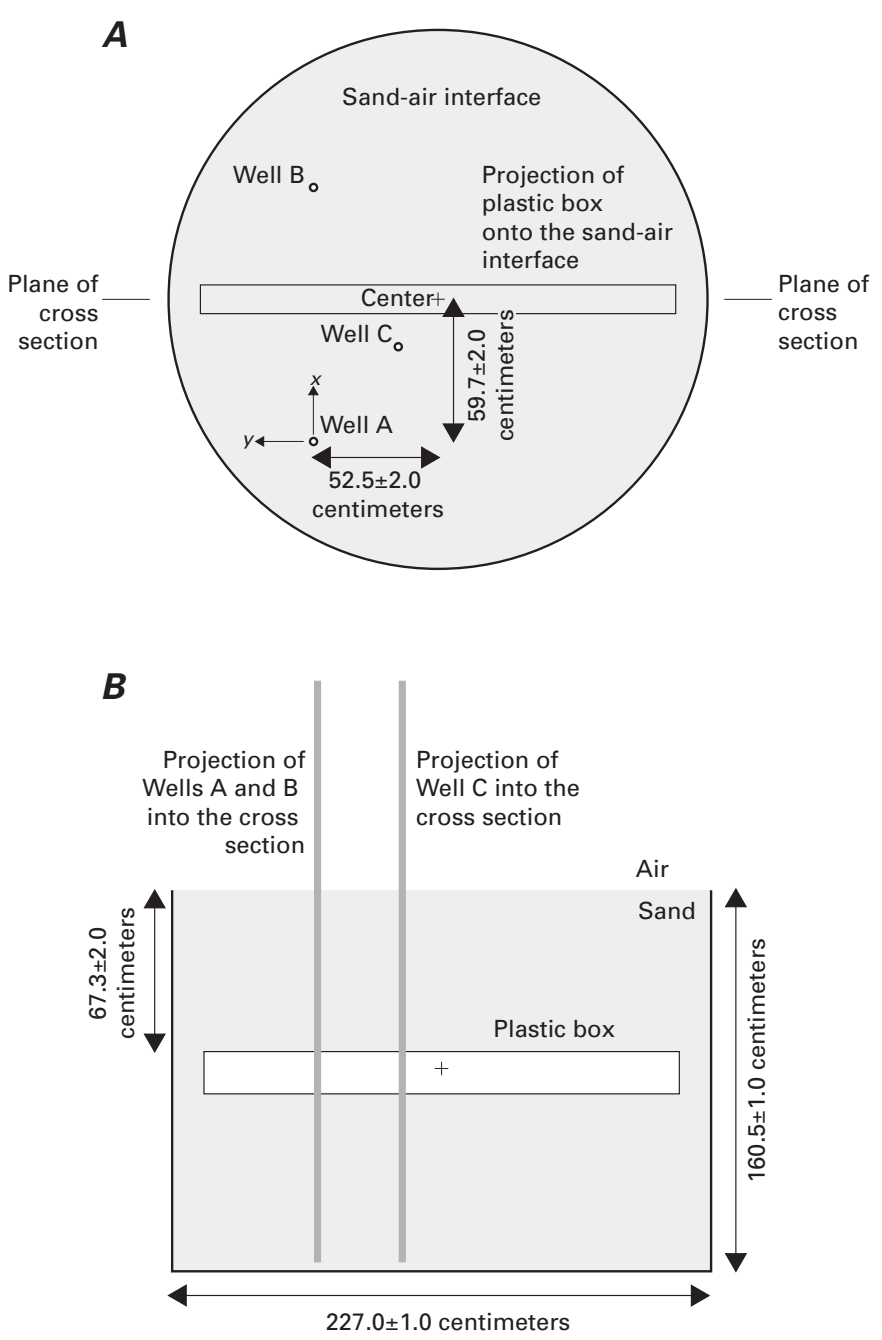

Figure 3. Schematic diagram of the laboratory tank; $(A)$ aerial view of the top of the tank; $(B)$ cross section through the middle of the tank.
The electromagnetic properties of the dry sand were measured in the U.S. Geological Survey Petrophysics Laboratory in Denver, Colorado. The measurements were made with a Hewlett Packard network analyzer using the method described in Olhoeft and Capron (1993). For one set of measurements, the sand was loose; whereas for another set, it was compacted. The frequencies range from 0.4 and $1.7 \mathrm{GHz}$ (fig. 6); this range includes the frequencies at which the crosswell radar data have high amplitudes. Both the relative dielectric permittivity and the relative magnetic permeability vary only slightly with frequency. In contrast, the electric conductivity increases significantly with frequency.

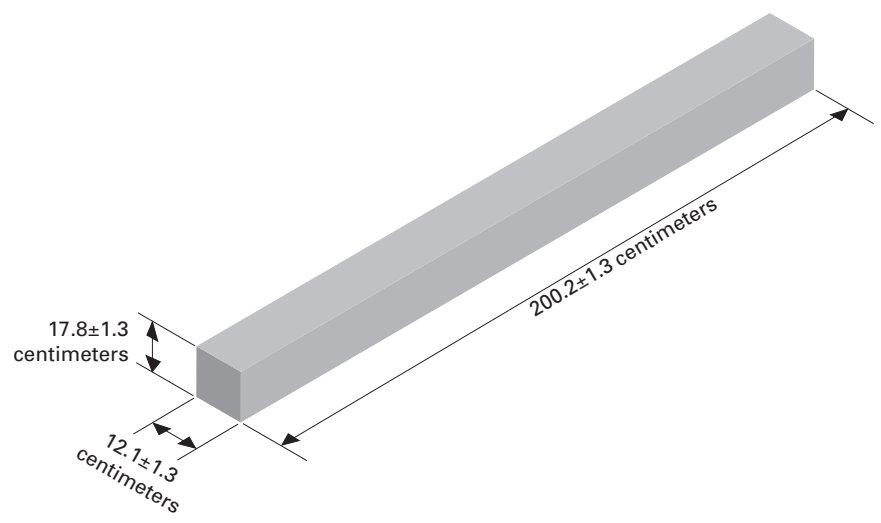

Figure 4. Schematic diagram of the plastic box.
A

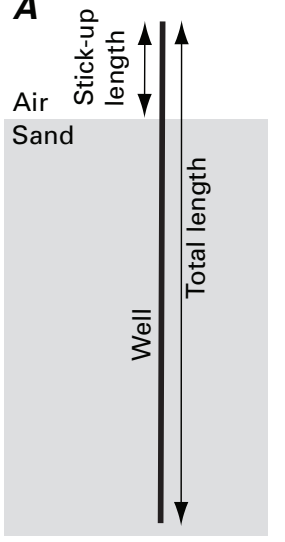

B

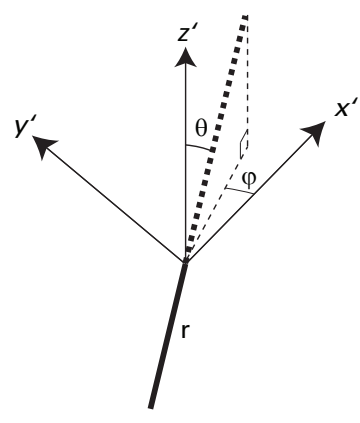

Radial distance (cable depth) Inclination

$\varphi \quad$ Azimuth

Well

Projection of well
Figure 5. Schematic diagrams of a well showing how various measurements of $(A)$ length and $(B)$ orientation are defined (table 1). In figure $5 B$, the well is shown with much more inclination than occurs in the laboratory tank to make clear the meaning of variables $r, \theta$, and $\varphi$ clear. 
Table 1. Measurements of wells. (The last four measurements are defined in figure 5.)

\begin{tabular}{cccccccc}
\hline Well & $\begin{array}{c}\text { x coordinate } \\
\text { of top } \\
\text { (centimeters) }\end{array}$ & $\begin{array}{c}\text { y coordinate } \\
\text { of top } \\
\text { (centimeters) }\end{array}$ & $\begin{array}{c}\text { z coordinate } \\
\text { of top } \\
\text { (centimeters) }\end{array}$ & $\begin{array}{c}\text { Total length } \\
\text { (centimeters) }\end{array}$ & $\begin{array}{c}\text { Stick-up length } \\
\text { (centimeters) }\end{array}$ & $\begin{array}{c}\text { Inclination } \\
\text { (degrees) }\end{array}$ & $\begin{array}{c}\text { Azimuth } \\
\text { (degrees) }\end{array}$ \\
\hline A & 0 & 0 & 0 & $244.1 \pm 0.1$ & $87.5 \pm 0.5$ & $0.18 \pm 0.01$ & $42 \pm 2$ \\
B & $107.1 \pm 0.1$ & 0 & $0.4 \pm 0.1$ & $244.4 \pm 0.1$ & $88.0 \pm 0.5$ & $0.54 \pm 0.04$ & $-76 \pm 3$ \\
C & $39.4 \pm 0.1$ & $-36.1 \pm 0.1$ & $1.0 \pm 0.1$ & $244.3 \pm 0.1$ & $87.7 \pm 0.5$ & $1.00 \pm 0.08$ \\
\hline
\end{tabular}
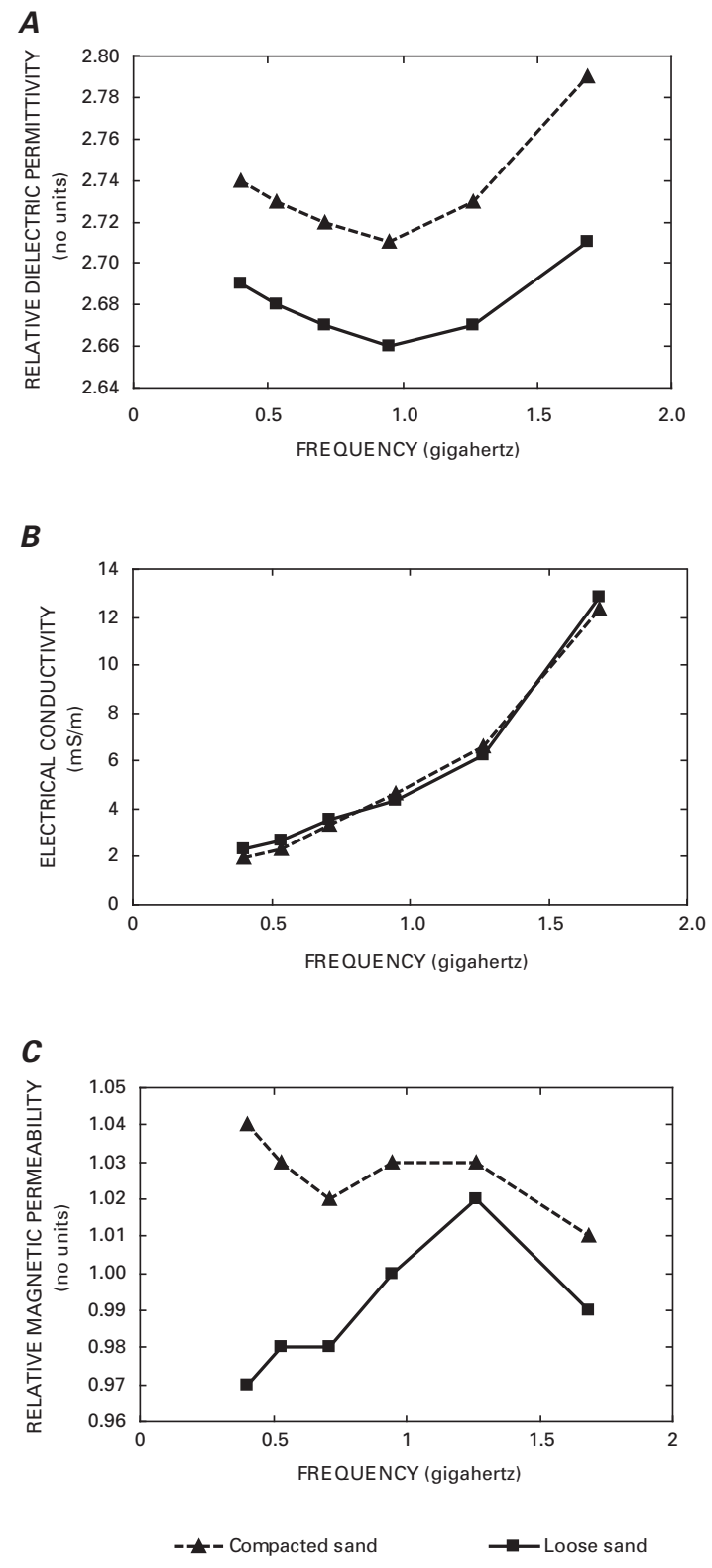

Figure 6. Electromagnetic properties of the dry sand; $(A)$ relative dielectric permittivity; $(B)$ electrical conductivity; $(C)$ relative magnetic permeability.

\section{Electronic System}

The transmitting antenna consists of two coaxial cables. The outer conductor of each cable is solid copper, and its outside diameter is $0.37 \mathrm{~cm}$ (fig. 7). The bottom cable is $3.3 \mathrm{~cm}$ long, the upper cable is $33.1 \mathrm{~cm}$ long, and the two cables are separated by a gap of $0.38 \mathrm{~cm}$. At the gap, the outer conductor of the lower cable is connected to the inner conductor of the upper cable. At $3.8 \mathrm{~cm}$ above the gap, the upper cable is surrounded by a string of 14 ferrite beads, which are held in place with black, heat-shrink tubing. The ferrite beads attenuate electromagnetic waves that propagate as guided waves.

The outer conductors of both coaxial cables are placed within a cylindrical nylon sheath, which protects them. The receiving antenna is identical to the transmitting antenna.

The coaxial cables attached to the transmitting and the receiving antennas have an impedance of $50 \mathrm{Ohms}(\Omega)$. For each cable, the attenuation equals approximately 2.5 decibels (dB) over its entire length; that is, the attenuation is small. (The attenuation measurement is at $1 \mathrm{GHz}$, which approximately equals the frequency with the highest amplitude in the radar data.) The ratio of electromagnetic energy outside the cable to that inside the cable is somewhat greater than $-100 \mathrm{~dB}$; that is, only a small amount of energy inside the cable leaks out. Conversely, only a small amount of energy outside the cable leaks in. These characteristics of the coaxial cables make them well suited for collecting crosswell radar data.

A schematic diagram of the electronic system is shown in figure 8 . The pulser generates a pulse with a peak amplitude of about 350 Volts (V) and a rise time of about 400 picoseconds (ps). The pulse propagates along a coaxial cable to the transmitting antenna. The pulse from the receiving antenna propagates along another coaxial cable to either an amplifier or an attenuator. (When the voltage is small, it is amplified so that the full dynamic range of the digitizer can be used. When the voltage is large, it is attenuated so that the digitizer is not saturated.) The digitizer is within the oscilloscope. After digitization, several traces are averaged to obtain one trace; this procedure, which is called "stacking," significantly diminishes random noise. The averaged trace is transferred to a personal computer. 
The trigger circuit continuously triggers the pulser at a 20 kilohertz (KHz) rate (fig. 8). When the pulser generates its $350 \mathrm{~V}$ pulse, some energy leaks out through the trigger input line, because of internal capacitance. This energy causes a voltage spike on the pulser trigger waveform that is then used as a trigger for the oscilloscope; this voltage spike provides accurate timing for the system. (This indirect method for obtaining the time is better than using a signal from the pulser output, because it does not load the output and thereby reduce its amplitude.)
The settings on the oscilloscope are controlled by software executing on a personal computer (fig. 8). This software also controls the collection of a trace. When either the computer mouse or the foot switch is actuated, the software sends a signal to the oscilloscope, requesting that it collect a trace. A collected trace is returned to the software, which records the trace, various settings for the oscilloscope, the location of the transmitting antenna, and the location of the receiving antenna.

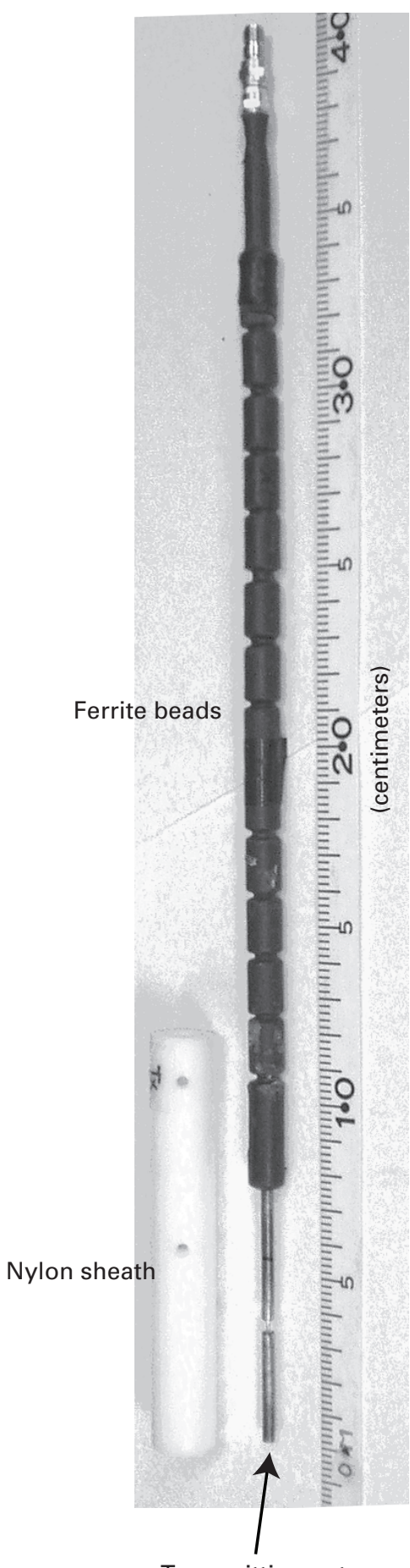

Figure 7. Transmitting antenna.

Transmitting antenna 


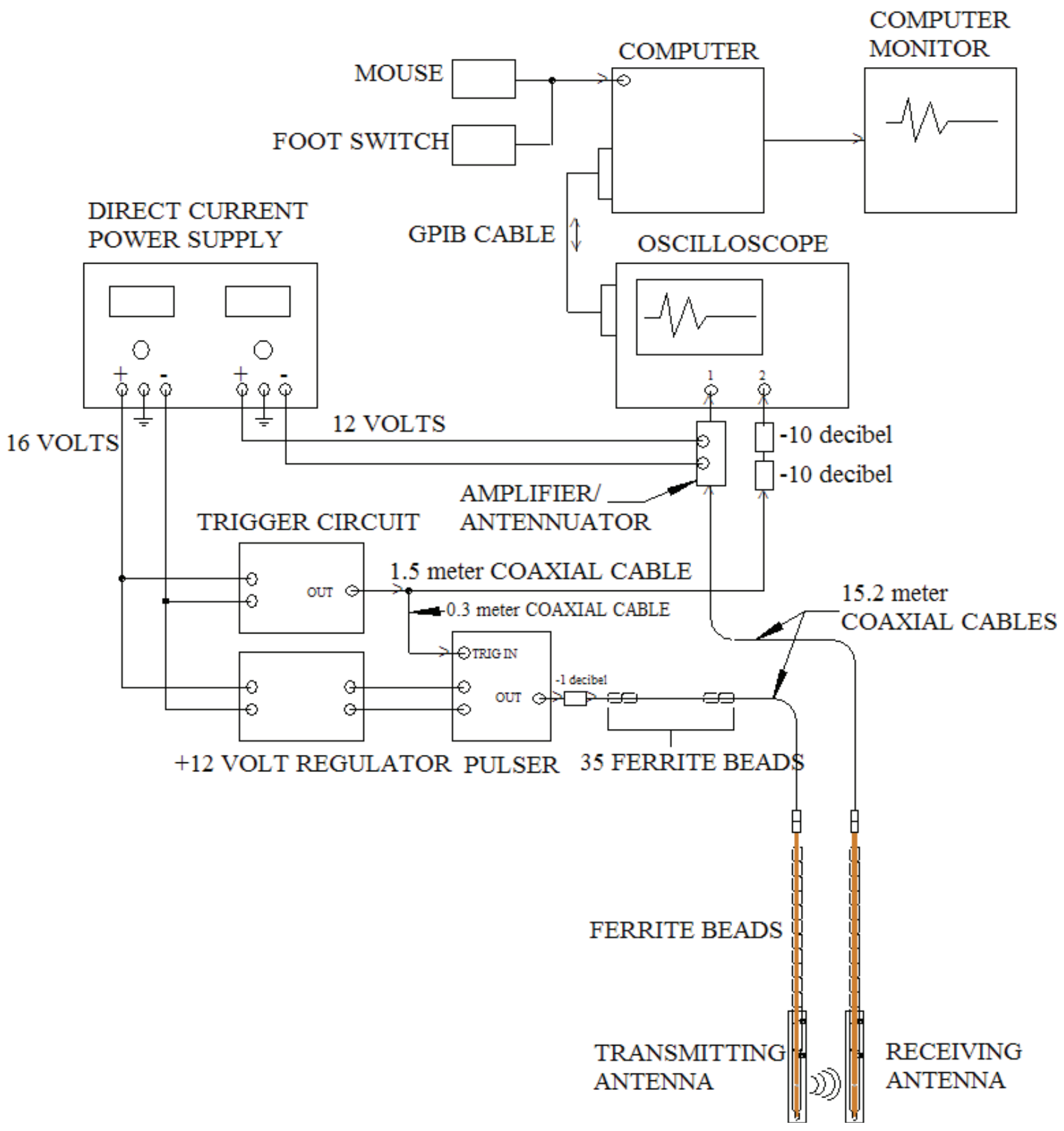

Figure 8. Schematic diagram of the electronic system. 


\section{Data Collection}

\section{Procedures}

The parameters used to collect the data were selected with a wave test and are listed in table 2 . The shortest wavelets in the data last about $1 \frac{1}{4}$ nanoseconds (ns). Because the sample interval is $40 \mathrm{ps}$, these wavelets are represented by about 30 samples, which is more than enough to accurately represent them. The sample interval corresponds to a Nyquist frequency of $12.5 \mathrm{GHz}$; this Nyquist frequency is much higher than the frequencies with high amplitudes in the traces, which range from about 0.5 to $1.5 \mathrm{GHz}$. Consequently, there is no frequency aliasing. The trace duration is $20 \mathrm{~ns}$, which is long enough to record all waves propagating between the two wells containing the antennas. Twenty stacks (that is, the number of prerecorded traces that are averaged to obtain one recorded trace) is large enough to significantly diminish the random noise.

The velocity of a radar wave in the sand is about $1.8 \times 10^{8}$ meters $/$ second $(\mathrm{m} / \mathrm{s})$, so the wavelengths range from about 12 to $36 \mathrm{~cm}$. The upper limit of spatial resolution for scalar diffraction tomography is half of the shortest wavelength (Born and Wolf, 1999, p. 713-716), and the same limit is assumed to apply to waveform inversion. If so, the antenna spacing should be less than $6 \mathrm{~cm}$. (The antenna spacing is the distance between successive locations of either antenna and is measured along the coaxial cable.) The chosen value of $4.5 \mathrm{~cm}$ (table 2) exceeds this criterion.

To collect the radar data, the transmitting antenna was lowered to the bottom of one well, and the receiving antenna was lowered to the bottom of another well. One radar trace was recorded for this configuration. The transmitting antenna was moved up $4.5 \mathrm{~cm}$ (table 2), and another trace

Table 2. Data-collection parameters.

\begin{tabular}{lc}
\hline \multicolumn{1}{c}{ Parameter } & Value \\
\hline Sample interval & 40 picoseconds \\
Number of samples & 500 \\
Number of stacks & 20 \\
Antenna spacing & $4.5 \pm 0.3$ centimeters \\
\hline
\end{tabular}

was recorded. These steps were repeated until the transmitting antenna was just below the sand-air interface. This collection of traces, which is called a "common-receiver gather," contains 33 traces. Next, the receiver antenna was moved up $4.5 \mathrm{~cm}$ (table 2), the transmitting antenna was lowered to the bottom of its well, and another common-receiver gather was collected. This procedure was repeated until the receiving antenna was just below the sand-air interface. Altogether 33 common-receiver gathers were collected.

To determine the time shifts that must be applied to the traces in the common-receiver gathers, additional traces were recorded: The transmitting and the receiving antennas were located at the same elevation just below the tops of their respective wells. That is, the antennas were above the sand-air interface, where the wells are in the air (fig. 2 and 5). (The maximum difference between the elevations of the two antennas was about $1.0 \mathrm{~cm}$.) About five traces were recorded; these five are called an "air-calibration gather." In each of these traces, the first wavelet is a wave that propagates through the air. Since the distance between the wells is known (table 1) and the speed of the radar wave in the air is known, the time required for the wave to propagate between the antennas can be calculated. The difference between this calculated time and the time picked from the traces is the required time shift.

Table 3 lists the order in which the two different gathers were recorded. First, an air-calibration gather was recorded, then five common-receiver gathers were recorded, then another air-calibration gather was recorded, and so on. At the end, another air-calibration gather was recorded. This procedure facilitates monitoring of the electronic system. Significant changes in the time shifts, if any, indicate that something in the electronic system changed. No significant changes were observed.

Six datasets were collected across the three wells (table 4). For example, between wells A and B, a dataset was collected with the receiving antenna in well $\mathrm{A}$ and the transmitting antenna in well B. Another dataset was collected with the antennas in the opposite wells. Because the distance between wells A and B is relatively large (table 1), the timevarying voltage from the receiving antenna was relatively small and required amplification. In contrast, because the distance between wells $\mathrm{A}$ and $\mathrm{C}$ is relatively small, the voltage was relatively large and required attenuation. Because the distance between wells $\mathrm{B}$ and $\mathrm{C}$ is moderate, the voltage required neither amplification nor attenuation. 
Table 3. Order in which the gathers were collected for a dataset.

\begin{tabular}{|c|c|c|}
\hline Order & Type of gather & File name \\
\hline 1 & air calibration & aircal1 \\
\hline 2 & common receiver & $\operatorname{crg} 1$ \\
\hline 3 & common receiver & $\operatorname{crg} 2$ \\
\hline 4 & common receiver & $\operatorname{crg} 3$ \\
\hline 5 & common receiver & $\operatorname{crg} 4$ \\
\hline 6 & common receiver & $\operatorname{crg} 5$ \\
\hline 7 & air calibration & aircal2 \\
\hline 8 & common receiver & $\operatorname{crg} 6$ \\
\hline 9 & common receiver & $\operatorname{crg} 7$ \\
\hline 10 & common receiver & $\operatorname{crg} 8$ \\
\hline 11 & common receiver & $\operatorname{crg} 9$ \\
\hline 12 & common receiver & $\operatorname{crg} 10$ \\
\hline 13 & air calibration & aircal3 \\
\hline 14 & common receiver & $\operatorname{crg} 11$ \\
\hline 15 & common receiver & $\operatorname{crg} 12$ \\
\hline 16 & common receiver & $\operatorname{crg} 13$ \\
\hline 17 & common receiver & $\operatorname{crg} 14$ \\
\hline 18 & common receiver & $\operatorname{crg} 15$ \\
\hline 19 & air calibration & aircal4 \\
\hline 20 & common receiver & $\operatorname{crg} 16$ \\
\hline 21 & common receiver & $\operatorname{crg} 17$ \\
\hline 22 & common receiver & $\operatorname{crg} 18$ \\
\hline 23 & common receiver & $\operatorname{crg} 19$ \\
\hline 24 & common receiver & $\operatorname{crg} 20$ \\
\hline 25 & air calibration & aircal5 \\
\hline 26 & common receiver & $\operatorname{crg} 21$ \\
\hline 27 & common receiver & $\operatorname{crg} 22$ \\
\hline 28 & common receiver & $\operatorname{crg} 23$ \\
\hline 29 & common receiver & $\operatorname{crg} 24$ \\
\hline 30 & common receiver & $\operatorname{crg} 25$ \\
\hline 31 & air calibration & aircal6 \\
\hline 32 & common receiver & $\operatorname{crg} 26$ \\
\hline 33 & common receiver & $\operatorname{crg} 27$ \\
\hline 34 & common receiver & $\operatorname{crg} 28$ \\
\hline 35 & common receiver & $\operatorname{crg} 29$ \\
\hline 36 & common receiver & $\operatorname{crg} 30$ \\
\hline 37 & air calibration & aircal7 \\
\hline 38 & common receiver & $\operatorname{crg} 31$ \\
\hline 39 & common receiver & $\operatorname{crg} 32$ \\
\hline 40 & common receiver & $\operatorname{crg} 33$ \\
\hline 41 & air calibration & aircal8 \\
\hline
\end{tabular}

Table 4. Datasets collected between the wells.

\begin{tabular}{lcccc}
\hline Directory & $\begin{array}{c}\text { Well with } \\
\text { receiving } \\
\text { antenna }\end{array}$ & $\begin{array}{c}\text { Well with } \\
\text { transmitting } \\
\text { antenna }\end{array}$ & $\begin{array}{c}\text { Amplifi- } \\
\text { cation } \\
\text { (decibels) }\end{array}$ & $\begin{array}{c}\text { Atten- } \\
\text { uation } \\
\text { (decibels) }\end{array}$ \\
\hline RxA_TxB & A & B & 10 & 0 \\
RxB_TxA & B & A & 10 & 0 \\
\hline RxB_TxC & B & C & 0 & 0 \\
RxC_TxB & C & B & 0 & 0 \\
RxC_TxA & C & A & 0 & 16 \\
\hline RxA_TxC & A & C & 0 & 16 \\
\hline
\end{tabular}

\section{Processing}

The radar traces, which were recorded by the electronic system (fig. 8), were converted to the format used within Seismic Un*x (Cohen and Stockwell, 2001). This format is referred to as the "SU format" and is a variant of the standard SEG Y format (Barry and others, 1975). The byte order for the files is little endian. Because the traces have a small bias, it was removed. The traveltimes from the air-calibration gathers were picked and used to compute time shifts. The estimated error in the time shifts is $\pm 80 \mathrm{ps}$, which corresponds to \pm 2 samples. The time shifts were then applied to the traces in the common receiver gathers so that origin time corresponds to the time that a radar wave started radiating from the transmitting antenna.

All data were converted to the SEG Y format, with little endian byte order. The converted data include the air-calibration gathers, the unprocessed common-receiver gathers, and the processed common-receiver gathers.

The SU and the SEG Y formats are designed for surface seismic data, not crosswell radar data. Consequently, three fields in the headers are used in a manner that differs from the format specifications:

1. The field for the sample interval, which is specified in microsecond, must be multiplied by $10^{-9}$ to get the correct sample interval. That is, this field is 40,000 microseconds $(\mu \mathrm{s})$ in all files; this value is multiplied by $10^{-9}$ to obtain $40 \mathrm{ps}$, the correct value. (If standard seismic software is used to display the radar data, then the units for time and frequency will appear to be seconds and Hertz, respectively. Because of the scaling, the correct units are nanoseconds and gigahertz, respectively.)

2. The field for the receiver group elevation records the cable depth of the receiving antenna. The cable depth is defined as the distance along the cable from the top of the well to the driving point of the antenna. The depth is chosen to be negative, and the unit for depth is millimeters.

3. The field for the source elevation records the cable depth of the transmitting antenna. 


\section{Antenna Locations}

To calculate the locations of an antenna, a temporary coordinate system was created at the top of the well containing the antenna (fig. $5 B$ ). (This temporary coordinate system is simply the translated coordinate system for the tank.) The well was assumed to be straight. (This approximation was checked by pushing a straight metal pipe down the well. The pipe reached to bottom of all wells, indicating that they are approximately straight.) Location within this coordinate system was calculated using spherical coordinates. The radius $(r)$ is the cable depth, the inclination $(\theta)$ is the angle from the positive $z^{\prime}$ axis, and the azimuth $(\varphi)$ is the angle from the positive $\mathrm{x}^{\prime}$ axis. The $\mathrm{x}^{\prime}$ location in the temporary coordinate system is $r \sin \theta \cos \varphi$, and the $\mathrm{x}$ location in the coordinate system for the tank is

$$
x=x_{w}+r \sin \theta \cos \varphi,
$$

where $x_{w}$ is the $x$ coordinate of the well containing the antenna (table 1). Likewise, the $y$ location is

$$
y=y_{w}+r \sin \theta \sin \varphi
$$

and the $z$ location is

$$
z=z_{w}+r \cos \theta
$$

Equations 1, 2, and 3 were used to calculate the locations listed in tables 5, 6, and 7 .

To show how the error in location is estimated, consider just the $x$ location (equation 1). The $x$ location plus the associated error $\delta x$, is

$$
x+\delta x=x_{w}+\delta x_{w}+(r+\delta r) \sin (\theta+\delta \theta) \cos (\varphi+\delta \varphi),
$$

where $\delta x_{w}$ is the error in the $x$ coordinate of the well containing the antenna, $\delta r$ is the error in the cable depth, $\delta \theta$ is the error in the inclination, and $\delta \varphi$ is the error in the azimuth (see tables 1 and 2). After some algebraic calculation, equation 4 reduces to

$$
\begin{gathered}
x+\delta x \cong x_{w}+\delta x_{w}+r \sin \theta \cos \varphi+(\sin \theta \cos \varphi) \delta r+ \\
(r \cos \theta \sin \varphi) \delta \theta-(r \sin \theta \cos \varphi) \delta \varphi,
\end{gathered}
$$

which includes only the first-order terms in $\delta r, \delta \theta$, and $\delta \varphi$. Equation 1 is subtracted from equation 5, yielding the estimated error in the $x$ location:

$$
\begin{gathered}
\delta x \cong \delta x_{w}+(\sin \theta \cos \varphi) \delta r+(r \cos \theta \sin \varphi) \delta \theta- \\
(r \sin \theta \cos \varphi) \delta \varphi .
\end{gathered}
$$

The derivations for estimated errors in $y$ and $z$ are similar, so they are not presented. The results are

$$
\begin{gathered}
\delta y \cong \delta \mathrm{y}_{\mathrm{w}}+(\sin \theta \cos \varphi) \delta r+(r \cos \theta \sin \varphi) \delta \theta+ \\
(r \sin \theta \cos \varphi) \delta \varphi
\end{gathered}
$$

\begin{tabular}{|c|c|c|c|}
\hline $\begin{array}{l}\text { Cable depth } \\
\text { (millimeters) }\end{array}$ & $\begin{array}{l}\text { x coordinate } \\
\text { (centimeters) }\end{array}$ & $\begin{array}{l}\text { y coordinate } \\
\text { (centimeters) }\end{array}$ & $\begin{array}{l}\text { z coordinate } \\
\text { (centimeters) }\end{array}$ \\
\hline-900 & $-0.2 \pm 0.0$ & $-0.2 \pm 0.0$ & $-90.0 \pm 0.3$ \\
\hline-945 & $-0.2 \pm 0.0$ & $-0.2 \pm 0.0$ & $-94.5 \pm 0.3$ \\
\hline-990 & $-0.2 \pm 0.0$ & $-0.2 \pm 0.0$ & $-99.0 \pm 0.3$ \\
\hline$-1,035$ & $-0.2 \pm 0.0$ & $-0.2 \pm 0.0$ & $-103.5 \pm 0.3$ \\
\hline$-1,080$ & $-0.3 \pm 0.0$ & $-0.2 \pm 0.0$ & $-108.0 \pm 0.3$ \\
\hline$-1,125$ & $-0.3 \pm 0.0$ & $-0.2 \pm 0.0$ & $-112.5 \pm 0.3$ \\
\hline$-1,170$ & $-0.3 \pm 0.0$ & $-0.2 \pm 0.0$ & $-117.0 \pm 0.3$ \\
\hline$-1,215$ & $-0.3 \pm 0.0$ & $-0.3 \pm 0.0$ & $-121.5 \pm 0.3$ \\
\hline$-1,260$ & $-0.3 \pm 0.0$ & $-0.3 \pm 0.0$ & $-126.0 \pm 0.3$ \\
\hline$-1,305$ & $-0.3 \pm 0.0$ & $-0.3 \pm 0.0$ & $-130.5 \pm 0.3$ \\
\hline$-1,350$ & $-0.3 \pm 0.0$ & $-0.3 \pm 0.0$ & $-135.0 \pm 0.3$ \\
\hline$-1,395$ & $-0.3 \pm 0.0$ & $-0.3 \pm 0.0$ & $-139.5 \pm 0.3$ \\
\hline$-1,440$ & $-0.3 \pm 0.0$ & $-0.3 \pm 0.0$ & $-144.0 \pm 0.3$ \\
\hline$-1,485$ & $-0.3 \pm 0.0$ & $-0.3 \pm 0.0$ & $-148.5 \pm 0.3$ \\
\hline$-1,530$ & $-0.4 \pm 0.0$ & $-0.3 \pm 0.0$ & $-153.0 \pm 0.3$ \\
\hline$-1,575$ & $-0.4 \pm 0.0$ & $-0.3 \pm 0.0$ & $-157.5 \pm 0.3$ \\
\hline$-1,620$ & $-0.4 \pm 0.0$ & $-0.3 \pm 0.0$ & $-162.0 \pm 0.3$ \\
\hline$-1,665$ & $-0.4 \pm 0.0$ & $-0.4 \pm 0.0$ & $-166.5 \pm 0.3$ \\
\hline$-1,710$ & $-0.4 \pm 0.0$ & $-0.4 \pm 0.0$ & $-171.0 \pm 0.3$ \\
\hline$-1,755$ & $-0.4 \pm 0.0$ & $-0.4 \pm 0.0$ & $-175.5 \pm 0.3$ \\
\hline$-1,800$ & $-0.4 \pm 0.0$ & $-0.4 \pm 0.0$ & $-180.0 \pm 0.3$ \\
\hline$-1,845$ & $-0.4 \pm 0.0$ & $-0.4 \pm 0.0$ & $-184.5 \pm 0.3$ \\
\hline$-1,890$ & $-0.4 \pm 0.0$ & $-0.4 \pm 0.0$ & $-189.0 \pm 0.3$ \\
\hline$-1,935$ & $-0.5 \pm 0.0$ & $-0.4 \pm 0.0$ & $-193.5 \pm 0.3$ \\
\hline$-1,980$ & $-0.5 \pm 0.0$ & $-0.4 \pm 0.0$ & $-198.0 \pm 0.3$ \\
\hline$-2,025$ & $-0.5 \pm 0.0$ & $-0.4 \pm 0.0$ & $-202.5 \pm 0.3$ \\
\hline$-2,070$ & $-0.5 \pm 0.0$ & $-0.4 \pm 0.0$ & $-207.0 \pm 0.3$ \\
\hline$-2,115$ & $-0.5 \pm 0.0$ & $-0.4 \pm 0.0$ & $-211.5 \pm 0.3$ \\
\hline$-2,160$ & $-0.5 \pm 0.0$ & $-0.5 \pm 0.0$ & $-216.0 \pm 0.3$ \\
\hline$-2,205$ & $-0.5 \pm 0.0$ & $-0.5 \pm 0.0$ & $-220.5 \pm 0.3$ \\
\hline$-2,250$ & $-0.5 \pm 0.0$ & $-0.5 \pm 0.0$ & $-225.0 \pm 0.3$ \\
\hline$-2,295$ & $-0.5 \pm 0.0$ & $-0.5 \pm 0.0$ & $-229.5 \pm 0.3$ \\
\hline$-2,340$ & $-0.5 \pm 0.0$ & $-0.5 \pm 0.0$ & $-234.0 \pm 0.3$ \\
\hline
\end{tabular}

and

$$
\delta z \cong \delta z_{w}+(\cos \theta) \delta r(r \sin \theta) \delta \theta .
$$

Equations 6, 7, and 8 were used to calculate the estimated errors listed in tables 5, 6, and 7 .

Table 5. Antenna locations for well A. The values for cable depth are those used in the file headers. 
Table 6. Antenna locations for well B. The values for cable depth are those used in the file headers.

\begin{tabular}{cccc}
\hline $\begin{array}{c}\text { Cable depth } \\
\text { (millimeters) }\end{array}$ & $\begin{array}{c}\text { x coordinate } \\
\text { (centimeters) }\end{array}$ & $\begin{array}{c}\text { y coordinate } \\
\text { (centimeters) }\end{array}$ & $\begin{array}{c}\text { z coordinate } \\
\text { (centimeters) }\end{array}$ \\
\hline-900 & $106.9 \pm 0.2$ & $0.8 \pm 0.0$ & $-89.6 \pm 0.4$ \\
-945 & $106.9 \pm 0.2$ & $0.9 \pm 0.0$ & $-94.1 \pm 0.4$ \\
-990 & $106.9 \pm 0.2$ & $0.9 \pm 0.1$ & $-98.6 \pm 0.4$ \\
$-1,035$ & $106.9 \pm 0.2$ & $0.9 \pm 0.1$ & $-103.1 \pm 0.4$ \\
$-1,080$ & $106.9 \pm 0.2$ & $1.0 \pm 0.1$ & $-107.6 \pm 0.4$ \\
$-1,125$ & $106.8 \pm 0.2$ & $1.0 \pm 0.1$ & $-112.1 \pm 0.4$ \\
$-1,170$ & $106.8 \pm 0.2$ & $1.1 \pm 0.1$ & $-116.6 \pm 0.4$ \\
$-1,215$ & $106.8 \pm 0.2$ & $1.1 \pm 0.1$ & $-121.1 \pm 0.4$ \\
$-1,260$ & $106.8 \pm 0.2$ & $1.2 \pm 0.1$ & $-125.6 \pm 0.4$ \\
$-1,305$ & $106.8 \pm 0.2$ & $1.2 \pm 0.1$ & $-130.1 \pm 0.4$ \\
$-1,350$ & $106.8 \pm 0.2$ & $1.2 \pm 0.1$ & $-134.6 \pm 0.4$ \\
$-1,395$ & $106.8 \pm 0.2$ & $1.3 \pm 0.1$ & $-139.1 \pm 0.4$ \\
\hline$-1,440$ & $106.8 \pm 0.2$ & $1.3 \pm 0.1$ & $-143.6 \pm 0.4$ \\
$-1,485$ & $106.8 \pm 0.2$ & $1.4 \pm 0.1$ & $-148.1 \pm 0.4$ \\
\hline$-1,530$ & $106.8 \pm 0.2$ & $1.4 \pm 0.1$ & $-152.6 \pm 0.4$ \\
$-1,575$ & $106.7 \pm 0.2$ & $1.4 \pm 0.1$ & $-157.1 \pm 0.4$ \\
\hline$-1,620$ & $106.7 \pm 0.2$ & $1.5 \pm 0.1$ & $-161.6 \pm 0.4$ \\
$-1,665$ & $106.7 \pm 0.2$ & $1.5 \pm 0.1$ & $-166.1 \pm 0.4$ \\
$-1,710$ & $106.7 \pm 0.2$ & $1.6 \pm 0.1$ & $-170.6 \pm 0.4$ \\
\hline$-1,755$ & $106.7 \pm 0.2$ & $1.6 \pm 0.1$ & $-175.1 \pm 0.4$ \\
\hline$-1,800$ & $106.7 \pm 0.2$ & $1.6 \pm 0.1$ & $-179.6 \pm 0.4$ \\
$-1,845$ & $106.7 \pm 0.2$ & $1.7 \pm 0.1$ & $-184.1 \pm 0.4$ \\
$-1,890$ & $106.7 \pm 0.2$ & $1.7 \pm 0.1$ & $-188.6 \pm 0.4$ \\
$-1,935$ & $106.7 \pm 0.2$ & $1.8 \pm 0.1$ & $-193.1 \pm 0.4$ \\
$-1,980$ & $106.6 \pm 0.2$ & $1.8 \pm 0.1$ & $-197.6 \pm 0.4$ \\
$-2,025$ & $106.6 \pm 0.2$ & $1.9 \pm 0.1$ & $-202.1 \pm 0.4$ \\
$-2,070$ & $106.6 \pm 0.2$ & $1.9 \pm 0.1$ & $-206.6 \pm 0.4$ \\
$-2,115$ & $106.6 \pm 0.2$ & $1.9 \pm 0.1$ & $-211.1 \pm 0.4$ \\
$-2,160$ & $106.6 \pm 0.2$ & $2.0 \pm 0.1$ & $-215.6 \pm 0.4$ \\
$-2,205$ & $106.6 \pm 0.2$ & $2.0 \pm 0.1$ & $-220.1 \pm 0.4$ \\
$-2,250$ & $106.6 \pm 0.2$ & $2.1 \pm 0.1$ & $-224.6 \pm 0.4$ \\
$-2,295$ & $106.6 \pm 0.2$ & $2.1 \pm 0.1$ & $-229.1 \pm 0.4$ \\
\hline-340 & $106.6 \pm 0.3$ & $2.1 \pm 0.1$ & $-233.6 \pm 0.4$ \\
\hline & & & \\
\hline
\end{tabular}

Table 7. Antenna locations for well C. The values for cable depth are those used in the file headers.

\begin{tabular}{|c|c|c|c|}
\hline $\begin{array}{l}\text { Cable depth } \\
\text { (millimeters) }\end{array}$ & $\begin{array}{l}\text { x coordinate } \\
\text { (centimeters) }\end{array}$ & $\begin{array}{l}\text { y coordinate } \\
\text { (centimeters) }\end{array}$ & $\begin{array}{l}\text { z coordinate } \\
\text { (centimeters) }\end{array}$ \\
\hline-900 & $38.1 \pm 0.2$ & $-35.2 \pm 0.1$ & $-89.0 \pm 0.4$ \\
\hline-945 & $38.1 \pm 0.2$ & $-35.1 \pm 0.1$ & $-93.5 \pm 0.4$ \\
\hline-990 & $38.0 \pm 0.2$ & $-35.1 \pm 0.1$ & $-98.0 \pm 0.4$ \\
\hline$-1,035$ & $37.9 \pm 0.2$ & $-35.0 \pm 0.1$ & $-102.5 \pm 0.4$ \\
\hline$-1,080$ & $37.9 \pm 0.3$ & $-35.0 \pm 0.1$ & $-107.0 \pm 0.4$ \\
\hline$-1,125$ & $37.8 \pm 0.3$ & $-34.9 \pm 0.1$ & $-111.5 \pm 0.4$ \\
\hline$-1,170$ & $37.7 \pm 0.3$ & $-34.9 \pm 0.1$ & $-116.0 \pm 0.4$ \\
\hline$-1,215$ & $37.7 \pm 0.3$ & $-34.9 \pm 0.1$ & $-120.5 \pm 0.4$ \\
\hline$-1,260$ & $37.6 \pm 0.3$ & $-34.8 \pm 0.1$ & $-125.0 \pm 0.4$ \\
\hline$-1,305$ & $37.6 \pm 0.3$ & $-34.8 \pm 0.1$ & $-129.5 \pm 0.4$ \\
\hline$-1,350$ & $37.5 \pm 0.3$ & $-34.7 \pm 0.1$ & $-134.0 \pm 0.4$ \\
\hline$-1,395$ & $37.4 \pm 0.3$ & $-34.7 \pm 0.1$ & $-138.5 \pm 0.4$ \\
\hline$-1,440$ & $37.4 \pm 0.3$ & $-34.6 \pm 0.1$ & $-143.0 \pm 0.4$ \\
\hline$-1,485$ & $37.3 \pm 0.3$ & $-34.6 \pm 0.1$ & $-147.5 \pm 0.4$ \\
\hline$-1,530$ & $37.2 \pm 0.3$ & $-34.5 \pm 0.1$ & $-152.0 \pm 0.4$ \\
\hline$-1,575$ & $37.2 \pm 0.3$ & $-34.5 \pm 0.1$ & $-156.5 \pm 0.4$ \\
\hline$-1,620$ & $37.1 \pm 0.3$ & $-34.4 \pm 0.2$ & $-161.0 \pm 0.4$ \\
\hline$-1,665$ & $37.0 \pm 0.3$ & $-34.4 \pm 0.2$ & $-165.5 \pm 0.4$ \\
\hline$-1,710$ & $37.0 \pm 0.4$ & $-34.3 \pm 0.2$ & $-170.0 \pm 0.4$ \\
\hline$-1,755$ & $36.9 \pm 0.4$ & $-34.3 \pm 0.2$ & $-174.5 \pm 0.4$ \\
\hline$-1,800$ & $36.9 \pm 0.4$ & $-34.3 \pm 0.2$ & $-179.0 \pm 0.4$ \\
\hline$-1,845$ & $36.8 \pm 0.4$ & $-34.2 \pm 0.2$ & $-183.5 \pm 0.4$ \\
\hline$-1,890$ & $36.7 \pm 0.4$ & $-34.2 \pm 0.2$ & $-188.0 \pm 0.4$ \\
\hline$-1,935$ & $36.7 \pm 0.4$ & $-34.1 \pm 0.2$ & $-192.5 \pm 0.4$ \\
\hline$-1,980$ & $36.6 \pm 0.4$ & $-34.1 \pm 0.2$ & $-197.0 \pm 0.4$ \\
\hline$-2,025$ & $36.5 \pm 0.4$ & $-34.0 \pm 0.2$ & $-201.5 \pm 0.4$ \\
\hline$-2,070$ & $36.5 \pm 0.4$ & $-34.0 \pm 0.2$ & $-206.0 \pm 0.4$ \\
\hline$-2,115$ & $36.4 \pm 0.4$ & $-33.9 \pm 0.2$ & $-210.5 \pm 0.4$ \\
\hline$-2,160$ & $36.4 \pm 0.4$ & $-33.9 \pm 0.2$ & $-215.0 \pm 0.4$ \\
\hline$-2,205$ & $36.3 \pm 0.4$ & $-33.8 \pm 0.2$ & $-219.5 \pm 0.4$ \\
\hline$-2,250$ & $36.2 \pm 0.4$ & $-33.8 \pm 0.2$ & $-224.0 \pm 0.4$ \\
\hline$-2,295$ & $36.2 \pm 0.4$ & $-33.7 \pm 0.2$ & $-228.5 \pm 0.4$ \\
\hline$-2,340$ & $36.1 \pm 0.4$ & $-33.7 \pm 0.2$ & $-233.0 \pm 0.4$ \\
\hline
\end{tabular}




\section{Discussion}

After the wave test (see the section Data Collection), the velocity of a radar wave in the dry sand was calculated to be $1.8 \times 10^{8} \mathrm{~m} / \mathrm{s}$. From this velocity $v$, the relative dielectric permittivity $\varepsilon_{r}$ is calculated with the formula $\varepsilon_{r} \cong(c / v)^{2}$, where $c$ is the velocity of light. The calculated relative dielectric permittivity is 2.8 , which differs from all laboratory measurements (fig. 6) by less than 4 percent.

For each processed dataset, the common-receiver gathers were sorted into a common-offset gather, with zero offset. (For this type of gather, the transmitting and the receiving antennas have the same cable depth. That is, they have approximately the same $z$ coordinate.) The gathers are displayed as images (fig. 9) because images show details in the wavefield that are difficult to discern in traces. The horizontal axis is time, for which $0 \mathrm{~ns}$ corresponds to time that the radar waves started radiating from the transmitting antenna. The vertical axis is the cable depth. At a cable depth of $-2,340 \mathrm{~mm}$, both antennas are near the bottom of the tank; at a cable depth of $-900 \mathrm{~mm}$, both antennas are just below the sand-air interface.
The two gathers associated with wells A and B (fig. 9A and $B$ ) appear identical, the two gathers associated with wells $B$ and $\mathrm{C}$ (fig. $9 C$ and $D$ ) appear identical, and the two gathers associated with wells $\mathrm{A}$ and $\mathrm{C}$ (fig. $9 E$ and $F$ ) appear identical. For each pair of wells, the apparent identicalness suggests that the two datasets were collected properly.

The various waves in the common-offset gathers are identified in figure 10. Examine the gather for wells $\mathrm{A}$ and B (fig. 10A). The direct wave propagated directly from the transmitting antenna to the receiving antenna, through the sand. When the two antennas were near the plastic box, the direct wave passed through the air-filled box, which decreased its traveltime. The head wave propagated through the sand, air, and sand in this order. The reflected wave from the sand-air interface propagated entirely within the sand, from the transmitting antenna to the interface and then to the receiving antenna. The reflected wave from the tank bottom is analogous. The gather includes various waves reflected from the side of the tank. In addition, the gather includes many low-amplitude waves after approximately $12 \mathrm{~ns}$; these waves are scattered from wells containing metal conductors that are located on the other side of the tank.
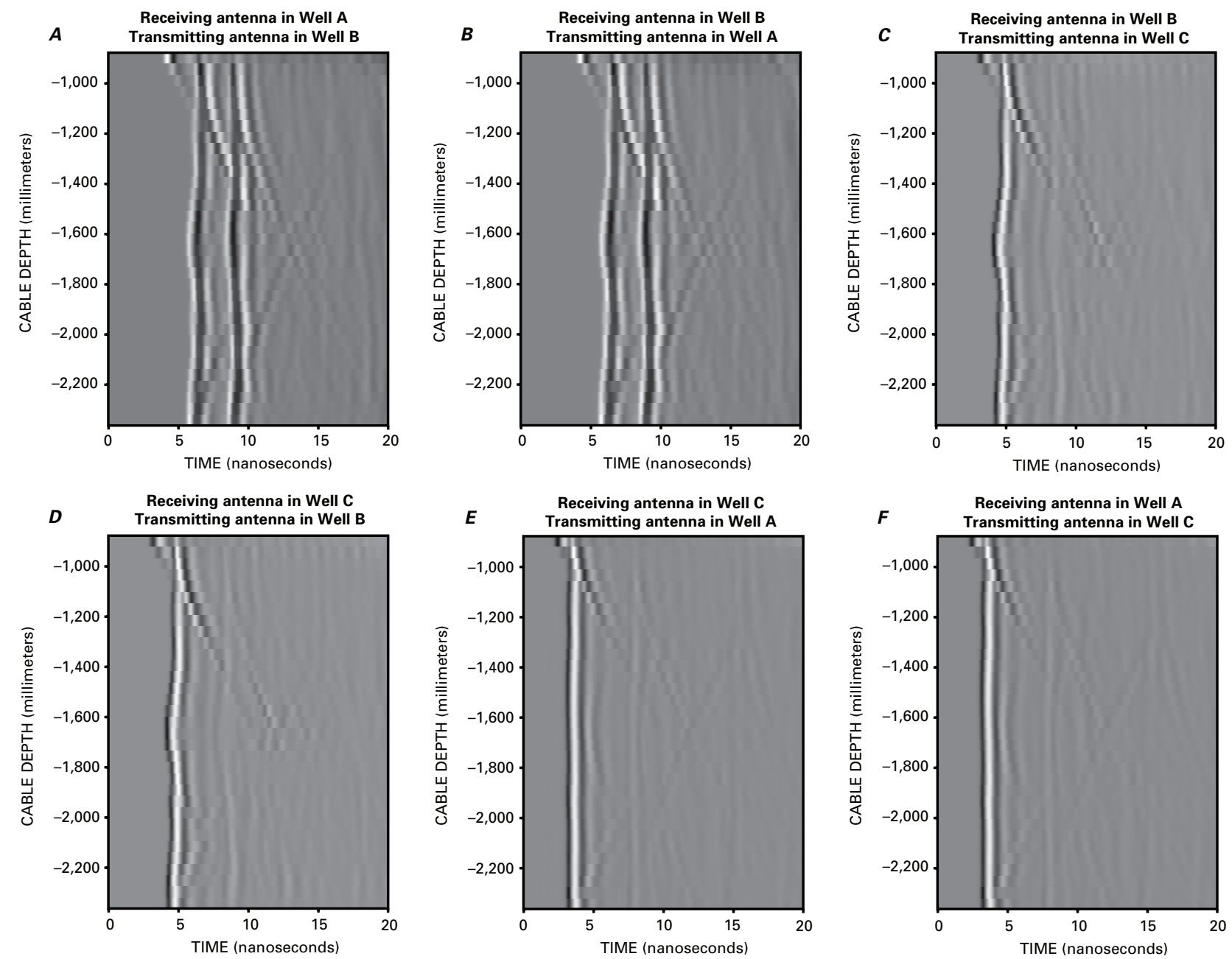

Figure 9. (A-F) Common-offset gathers (with zero offset) for the 6 datasets. 

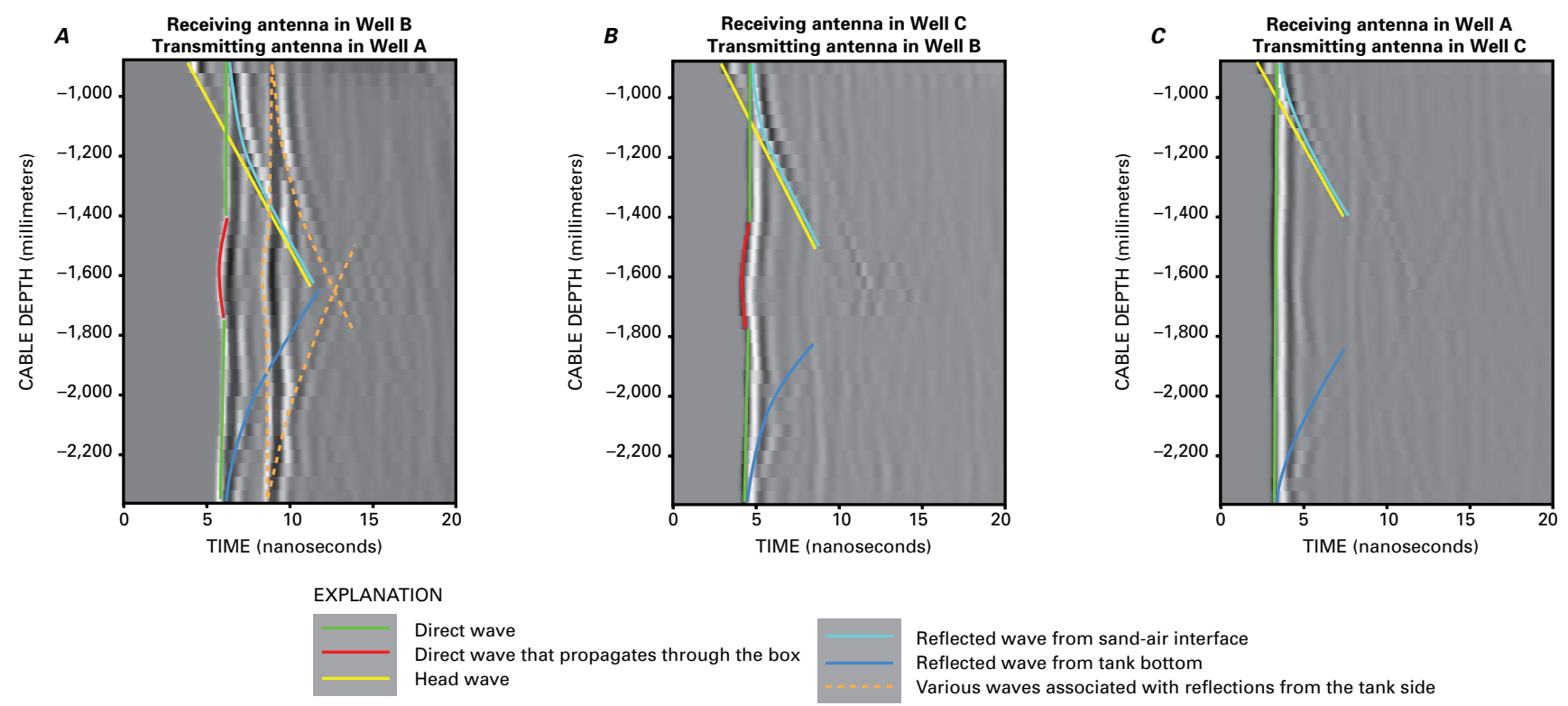

Reflected wave from sand-air interface Reflected wave from tank bottom

Various waves associated with reflections from the tank side

Figure 10. $(A-C)$ Three common-offset gathers. The colored lines indicate the wave type.

Compare the common-offset gather for wells A and B to the other two gathers (fig. 10). All three gathers have the same waves, with one exception. The exception pertains to the gather for wells $\mathrm{A}$ and $\mathrm{C}$, which lacks the anomaly in the direct wave because of the plastic box. The reason is that the box is outside the vertical plane passing through the two wells (fig. 3). Among the three gathers, the attributes of the waves differ. Although there are many differences, the following two are especially important:

1. The wave polarities in figure $10 A$ are opposite of those in figures $10 B$ and $C$. The change in polarity is caused by the amplifier that was needed to collect the data between wells A and B (table 4).

2. The two gathers in figures $10 B$ and $C$ include reflected waves from the tank side, but these reflected waves have relatively low amplitude because the distance to the tank side is long compared to the distance between the wells.

At least three features of these datasets make the datasets suitable for evaluating algorithms that process crosswell radar data. First, the properties of the dry sand and the plastic box are measured independently of the radar surveys (fig. 4 and 6). These measured values can be compared to the properties estimated by the processing algorithms. Second, the locations of the antennas include estimates of the errors (tables 5, 6, and 7). Such errors affect the images of the estimated properties (for example, velocity), and the magnitude of this effect can be determined for various algorithms. Third, each pair of wells is associated with two datasets (table 4). The two images from the two datasets correspond to the same region, so they can be compared pixel by pixel to determine the variations in the estimated properties. Likewise, each well is associated with four different datasets (table 4). For example, well A is associated with two datasets between wells A and B and with two datasets between wells A and $\mathrm{C}$. The four images from the four datasets overlap at well A, here the pixels also can be compared to determine the variations in the estimated properties.

Although these datasets pertain to a laboratory setting, they scale to a typical field setting. To understand this claim, consider the laboratory data at $0.9 \mathrm{GHZ}$, which is the peak frequency. Using an average velocity of $1.8 \times 10^{8} \mathrm{~m} / \mathrm{s}$, the wavelength is $0.20 \mathrm{~m}$. For a typical field survey, the relative dielectric permittivity might be 5 , and the peak frequency might be $60 \mathrm{MHz}$. For this case, the wavelength is $2.2 \mathrm{~m}$. The ratio of the two wavelengths is 11; this ratio multiplies all distances to obtain field-equivalent values. For example, fieldequivalent distance between wells A and B is $11.8 \mathrm{~m}$, which is typical of many field surveys. 


\section{Organization of Data Files}

Each of the six datasets is in a separate directory, whose name is listed in table 4 . The organization of all directories is identical, so consider only one directory, for example

"RxA_TxB." This directory contains four subdirectories:

1. "UnprocessedSuData" contains the unprocessed common-receiver gathers and the air-calibration gathers, which are both in SU format.

2. "UnprocessedSegyData" contains the unprocessed common-receiver gathers and the air-calibration gathers, which are both in SEG Y format.

3. "ProcessedSuData" contains the processed commonreceiver gathers in $\mathrm{SU}$ format.

4. "ProcessedSegyData" contains the processed commonreceiver gathers in SEG Y format.

For all four subdirectories, the file names of the gathers are listed in table 3. For those gathers stored in the SU format, the suffix of the filename is "su." For those gathers stored in the SEG Y format, the suffix of the filename is "sgy."

\section{Acknowledgments}

Chad E. Ailes, Jonah Sullivan, and Burke J. Minsley designed and built the laboratory tank. Jeffery E. Lucius and Richard B. Wanty measured locations with a survey.

\section{References}

Barry, K.M., Cavers, D.A., and Kneale, C.W., 1975, Report on recommended standards for digital tape formats: Geophysics, v. 40, p. 344-352.

Born, Max, and Wolf, Emil, 1999, Principles of opticsElectromagnetic theory of propagation, interference, and diffraction of light, 7th edition: Cambridge University Press, $952 \mathrm{p}$.

Cohen, J.K., and Stockwell Jr., J.W., 2001, CWP/SU-Seismic Un*x Release No. 35-An open source software package for seismic research and processing: Center for Wave Phenomena, Colorado School of Mines, available online at http://timna.mines.edu/cwpcodes/ (Accessed September 2009).

Olhoeft, G.R., and Capron, D.E., 1993, Laboratory measurements of the radiofrequency electrical and magnetic properties of soils from near Yuma, Arizona: U.S. Geological Survey Open-File Report 93-701, 214 p.

Paillet, F.L., and Ellefsen, K.J., 2005, Downhole applications of geophysics in Butler, D.K, ed., Near-surface geophysics, part 1: Tulsa, Oklahoma, Society of Exploration of Geophysicists, p. 439-471.

Publishing support provided by:

Denver Publishing Service Center

For more information concerning this publication, contact:

Team Chief Scientist, USGS Crustal Imaging and Characterization

Box 25046, Mail Stop 964

Denver, CO 80225

(303) 236-1312

Or visit the Crustal Imaging and Characterization Team Web site at: http://crustal.usgs.gov/ 
